\title{
Translating batch electrochemistry to single-pass continuous flow conditions: an organic chemist's guide
}

\author{
Snjezana Maljuric ${ }^{1,2} \cdot$ Wolfgang Jud $^{1,2} \cdot$ C. Oliver Kappe ${ }^{1,2}$ (D) David Cantillo ${ }^{1,2}$ (I)
}

Received: 6 October 2019 / Accepted: 17 October 2019 / Published online: 17 February 2020

(C) The Author(s) 2020

\begin{abstract}
The recent renaissance of electrochemical methods for organic synthesis has also attracted increased interest towards flow electrochemistry as the most suitable scale-up strategy. Many electrochemical methods using flow cells are based on recirculation of the electrolyte solution. However, single-pass processing is very attractive as it permits integration of the electrochemical reaction with other synthetic or purification steps in a continuous stream. Translation of batch electrochemical procedures to single-pass continuous flow cells can be challenging to beginners in the field. Using the electrochemical methoxylation of 4methylanisole as model, this paper provides newcomers to the field with an overview of the factors that need to be considered to develop a flow electrochemical process, including advantages and disadvantages of operating in galvanostatic and potentiostatic mode in small scale reactions, and the effect of the interelectrode gap, supporting electrolyte concentration and pressure on the reaction performance. A comparison of the reaction efficiency in batch and flow is also presented.
\end{abstract}

Keywords Organic electrochemistry. Methoxylation · Narrow gap cell · Continuous flow electrochemistry

\section{Introduction}

During the past few years, the organic chemistry community has witnessed a remarkable renaissance of electrochemical methods [1-3]. Electrochemistry provides some of the greenest synthetic strategies, as the use of stoichiometric amounts of often hazardous or waste-generating oxidants or reductants can be substituted by electricity and simple electron acceptors or donors such as water $[4,5]$. In addition to reduced waste generation, the atom economy of electrochemical methods is most often

Electronic supplementary material The online version of this article (https://doi.org/10.1007/s41981-019-00050-z) contains supplementary material, which is available to authorized users.

C. Oliver Kappe

oliver.kappe@uni-graz.at

$\triangle$ David Cantillo

david.cantillo@uni-graz.at

1 Institute of Chemistry, University of Graz, NAWI Graz, Heinrichstrasse 28, 8010 Graz, Austria

2 Center for Continuous Flow Synthesis and Processing (CCFLOW), Research Center Pharmaceutical Engineering GmbH (RCPE), Inffeldgasse 13, 8010 Graz, Austria superior to conventional procedures. The resurgence of organic electrochemistry has been accompanied by an increased attention to flow electrochemistry [6-10]. Implementation of flow cells is widely recognized as the appropriate method for the scale-up of electrochemistry. Indeed, some of the largest scale chemical production processes, like the chlor-alkali process, are based on continuous flow electrochemistry [11].

Flow cells typically consist of two flat electrodes placed in parallel with a narrow distance $(<1 \mathrm{~mm})$ between them [6-10]. The solution of reactants solution is then flown through the gap, where the electrolysis occurs. This configuration, often called parallel plate cell, minimizes the resistance of the electrolyte, which is proportional to the interelectrode distance, enabling the application of higher currents and lower concentrations of supporting electrolyte. Mass transfer, of key importance in the kinetics of electrochemical reactions, is typically enhanced in flow cells [9, 10]. Mass transfer can be further improved if the flow cell is equipped with "turbulence promoters." [12] In addition, flow cells exhibit a very high electrode surface area to reaction volume ratio, which also increases the speed with which the electrolysis can be performed. Scale-up of flow electrochemical processes is achieved by stacking several cells in a filter-press arrangement $[9,13]$. 
Electrochemical reactions in flow cells are very often carried out with recirculation of the electrolyte solution, which is held in a reservoir (Fig. 1a). This mode of operation benefits from the above-mentioned enhanced cell conductivity, improved mass transfer, and high electrode surface area to reaction volume ratio [8-10]. However, this semi-batch type operation is not a genuine continuous process, as a constant stream of product solution is not obtained from the setup. Fully continuous processes can be achieved if high conversion to the desired product is achieved in a single pass through the flow cell. In this type of reactor operation, the electrolyte solution is collected in a separate container after the flow cell (Fig. 1b). Single-pass operation enables the potential integration of the electrochemical reaction with other synthetic or workup steps in a continuous sequence $[10,14,15]$. Thus, development of single-pass continuous flow electrochemical procedures and flow reactors suitable for this type of operation is highly desirable. Several methods to achieve high conversions with electrochemical flow cells in a single pass have been proposed [9]. In addition to the possibility of simply decreasing the flow rate, increased electrode surface area with three-dimensional electrode materials (e.g. carbon felt) [16, 17] or extended reactor channel length reactors have been proposed [18-25].

Translating an electrochemical reaction from a conventional undivided batch reactor to a flow cell with solution recycle can be relatively simple. The solution is pumped through the cell with certain flow rate. In this case, as the conversion obtained in a reactor pass is not relevant for the overall reaction, high flow rates are indeed beneficial due to the improved mass transfer obtained if turbulent flow is achieved. Ultimately, the amount of charge applied to the mixture and the conversion depends on the current of the cell and the initial quantity of reactants in the electrolyte reservoir. In contrast, translation of a batch electrosynthesis to a single-pass continuous flow process can be more challenging. Cell current and flow rate have to be adjusted to achieve high conversion in a single pass. Although current and flow rate values can be estimated using Faraday's law [9, 13], several reaction parameters, including the flow rate itself, affect the current efficiency of the cell. Other important factors that affect the cell efficiency include the interelectrode gap distance, the amount of supporting electrolyte, or the generation of gas when anodic oxidations are carried out with concurrent proton reduction on the cathode.

The engineering aspects and behavior of parallel plate flow electrochemical cells have been described by several treatises of great value for electrochemical engineers $[11,26]$. The contributions by Brown, Pletcher, and Walsh in this area of organic electrochemistry in flow cells are noteworthy $[9,13$, 27, 28]. Yet, synthetic organic chemists have rarely employed electrochemical synthesis as a routine method in the past $[29$, 30]. Utilization of electrochemical methods in continuous flow mode is even more scarce. The barrier to synthetic organic chemists implementing electroorganic synthesis as a routine tool can be ascribed to a lack of familiarity with the physics behind electrochemical methods as well as with important parameters such as electrode materials and nature of the supporting electrolyte. Under continuous flow conditions, additional aspects like the flow rates or interelectrode distance play an important role. Particularly on small scale and for single-pass mode, non-specialists need to familiarize themselves with chemical engineering concepts like steady-state conditions or liquid flow velocity, and identify when to operate under galvanostatic or potentiostatic mode.

This paper aims to provide guidance for beginners in the area of flow electrochemistry for the translation of batch procedures to single-pass continuous flow conditions. The advantages and disadvantages of operating in galvanostatic and potentiostatic mode in small-scale reactions, and the effect of the interelectrode gap, supporting electrolyte concentration and pressure on the reaction performance and current efficiency are presented. For this purpose, the methoxylation of 4methylanisole, a well-known electrosynthesis of industrial importance, has been investigated in depth under a wide range of reaction conditions using a commercially available flow cell.

\section{Results and discussion}

\section{Model reaction and batch experiments}

The electrochemical methoxylation of 4-methylanisole was selected as model reaction for this study. This well-known
Fig. 1 Semi-batch solution recirculation $\mathbf{a}$ and single-pass $\mathbf{b}$ operation in a flow electrochemical cell (a)

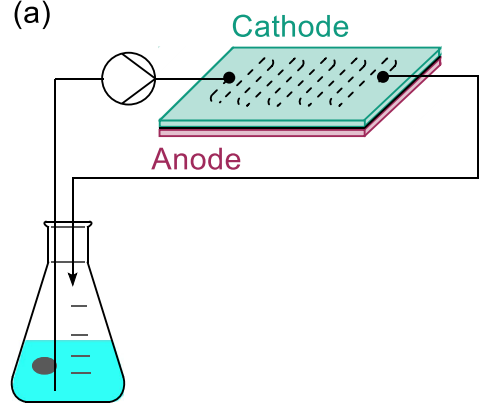

(b)

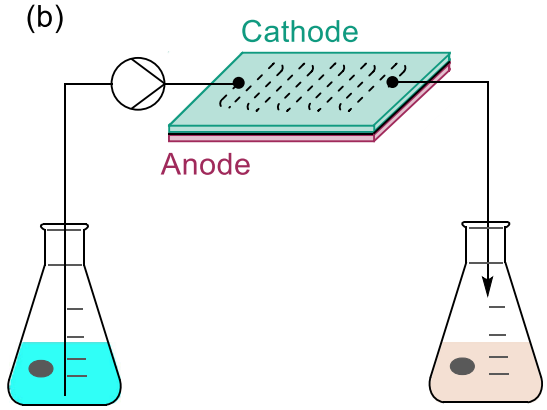


transformation is carried out on a large scale at BASF using graphite disk electrodes in a narrow-gap arrangement and recirculation of the electrolyte $[11,13]$. It is very often utilized as model for the evaluation of electrochemical flow cells [20, 31-34]. A 2-electron anodic oxidation of the benzylic group in methanol provokes its acetalization (Scheme 1). Formation of the desired diacetal 3 occurs after a second 2-electron oxidation step. The process therefore requires a theoretical charge of $4 \mathrm{~F} / \mathrm{mol}$ for completion. Acidic workup of the diacetal yields the desired aldehyde $\mathbf{3}^{\prime}$. If too much charge is applied to the reaction mixture, compound $\mathbf{4}$ is formed. Its acidic workup produces the corresponding methyl ester $4^{\prime}$. Reduction of protons from the methanol on the cathode produces hydrogen gas as byproduct.

Batch experiments were carried out in a commercial reactor (IKA ElectraSyn 2.0) using graphite as the anode material and graphite or stainless steel as the cathode. In a typical experiment, a standard 5-mL vial was loaded with a solution of 4methylanisole $(0.1 \mathrm{M})$ and a variable amount of $\mathrm{Et}_{4} \mathrm{NBF}_{4}$ as supporting electrolyte in methanol $(3 \mathrm{~mL})$. A current of $20 \mathrm{~mA}$ (current density ca. $13 \mathrm{~mA} / \mathrm{cm}^{2}$ ) was applied until a charge of 1-6 F/mol had been passed through the solution (Table 1). Graphite and stainless steel as cathode material provided similar results. The conversion was slightly higher with stainless steel as a cathode when charge amounts up to 4 F/mol were applied (entries 1-4). After an excess of charge had been passed, the reaction using stainless steel as a cathode material showed a better performance. Thus, higher conversion, current efficiency, and GC yield for compound $\mathbf{2}$ were observed (Table 1, entry 5). Notably, the current efficiency remained essentially constant with a value of ca. $60 \%$ independently of the amount of charge passed. This nearly constant value could indicate that the efficiency is independent of the concentration of the substrate (1), at least at conversions of up to $90 \%$.

\section{Continuous flow setup}

Continuous flow experiments were carried out using a commercial parallel plates flow cell (Vapourtec Ion Reactor) [35]. The reactor consisted of two electrodes $(5 \times 5 \mathrm{~cm})$ separated by PTFE or FEP spacers of variable thickness. The surface area of the electrode exposed to the reaction mixture was $2 \times$ $12 \mathrm{~cm}^{2}$. Graphite was utilized as the anode material. For the cathode, graphite or 304 stainless steel was utilized. The reaction mixture was introduced into the reactor using a $1.5-\mathrm{mL}$ sample loop and a 6-port valve (Fig. 2). The reactor was pressurized in some cases (vide infra) using an adjustable backpressure regulator (BPR). A programmable laboratory power supply was utilized to electrify the flow cell. The current and/ or voltage of the cell was simultaneously monitored using a digital multimeter (see the "Experimental section" for details)

\section{Galvanostatic vs potentiostatic operation in continuous flow}

Electrochemical reactions in galvanostatic mode are carried out under constant current. The voltage of the cell is variable and adapts to the reaction conditions to achieve the set current. The amount of charge applied to the reaction mixture can be easily calculated from the value of the current using Faraday's law (Eq. 1), where $I$ is the current, $\dot{V}$ is the flow rate in milliliter per minute, $c$ the concentration of the substrate in solution in

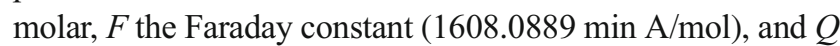
the amount of charge in $\mathrm{F} / \mathrm{mol}$. The same equation can be utilized to calculate the flow rate/current ratio for a given amount of charge and substrate concentration. During potentiostatic operation, the cell voltage is set to a constant value and the cell current is variable.

$Q=\frac{I}{\dot{V} \times c \times F}$

Constant current is the most common mode of operation of continuous flow cells $[9,12]$. More robust results are typically achieved under constant current, as the current density is known and reproducible and the desired amount of charge being applied to the reaction mixture can be achieved by adjusting the current [13]. Constant voltage operation can be more problematic, especially if a two-electrode configuration is utilized, because the cell voltage can be influenced by many
Scheme 1 Anodic methoxylation of 4-methylanisole

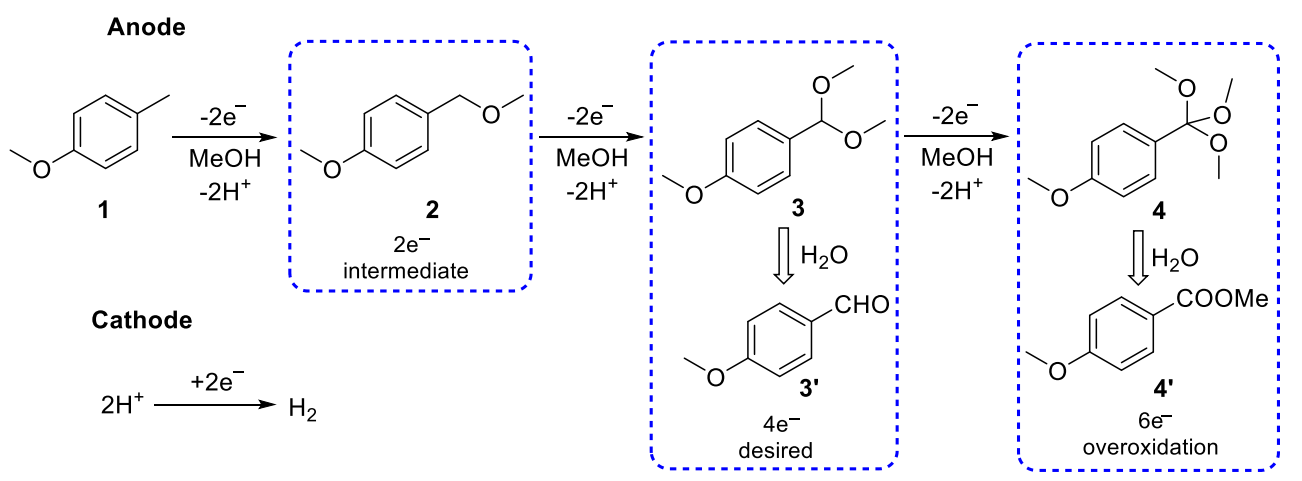


Table 1 Electrochemical methoxylation of $\mathbf{1}$ in a batch reactor $^{\mathrm{a}}$

\begin{tabular}{|c|c|c|c|c|c|}
\hline \multirow[t]{2}{*}{ Entry } & \multirow[t]{2}{*}{$\mathrm{Q}(\mathrm{F} / \mathrm{mol})$} & \multicolumn{2}{|l|}{$\mathrm{C}(+) / \mathrm{Fe}(-)$} & \multicolumn{2}{|l|}{$\mathrm{C}(+) / \mathrm{C}(-)$} \\
\hline & & Conv. ${ }^{\mathrm{b}} / \mathrm{CE}^{\mathrm{c}}(\%)$ & $2,3,4(\%)^{\mathrm{b}}$ & Conv. ${ }^{\mathrm{b}} / \mathrm{CE}^{\mathrm{c}}(\%)$ & $2,3,4(\%)^{\mathrm{b}}$ \\
\hline 1 & 1 & $21 / 63$ & $10,11,<1$ & $20 / 59$ & $10,10,<1$ \\
\hline 2 & 2 & $38 / 61$ & $15,23,<1$ & $37 / 58$ & $14,22,<1$ \\
\hline 3 & 3 & $53 / 61$ & $15,38,<1$ & $52 / 57$ & $16,35,<1$ \\
\hline 4 & 4 & $69 / 62$ & $14,55,<1$ & $64 / 55$ & $15,47,<1$ \\
\hline 5 & 6 & $91 / 60$ & $5,84,2$ & $81 / 48$ & $11,64,2$ \\
\hline
\end{tabular}

${ }^{\mathrm{a}}$ Reaction conditions: $0.1 \mathrm{M}$ 4-methylanisole and $0.1 \mathrm{M} \mathrm{Et}_{4} \mathrm{NBF}_{4}$ in $3 \mathrm{~mL}$ methanol, $20 \mathrm{~mA}$ constant current (ca. $\left.13 \mathrm{~mA} / \mathrm{cm}^{2}\right), 800 \mathrm{rpm}$

b Determined by GC-FID peak area percentage

${ }^{\mathrm{c}} C E$ current efficiency, calculated as the proportion of charge effectively utilized for methoxylation, including 2 , 3 , and 4

parameters, including temperature, small amounts of impurities in the reaction mixture, or even external factors such as contact issues between the cell and the power supply [13]. Moreover, small variations in the cell voltage can lead to dramatic changes in the current and ultimately in the amount of charge applied to the mixture. This is especially relevant for single-pass continuous flow reactions.

During lab scale optimization of continuous flow reactions, it is commonplace to use small amounts of reagents, in some instances introducing the solutions into the reactor with the aid of sample injectors. It should be noted that, under galvanostatic mode, current should only be applied to the flow cell under steady-state conditions (i.e., when the cell is filled with solution and its concentration is constant). If current is applied too early or in a later stage when the amount of substrate in the flow cell is too low, high amounts of undesired overoxidation products may occur, which in some cases could provoke further issues such as clogging of the cell or electrode fouling.

To illustrate the importance of applying constant current only under steady-state conditions, we carried out the model reaction using the continuous flow setup depicted in Fig. 2 and an interelectrode gap of $0.1 \mathrm{~mm}$. The sample loop was loaded with a solution of $1(0.1 \mathrm{M})$ and $\mathrm{Et}_{4} \mathrm{NBF}_{4}(0.1 \mathrm{M})$ in $\mathrm{MeOH}$. A flow rate of $400 \mu \mathrm{L} / \mathrm{min}$ and a constant current of $257 \mathrm{~mA}$ (4 $\mathrm{F} / \mathrm{mol}$ ) was applied during the whole process. To avoid major issues with undesired oxidations (e.g., solvent oxidation or
Fig. 2 Schematic view of the continuous flow setup utilized for the electrochemical methoxylation of $\mathbf{1}$

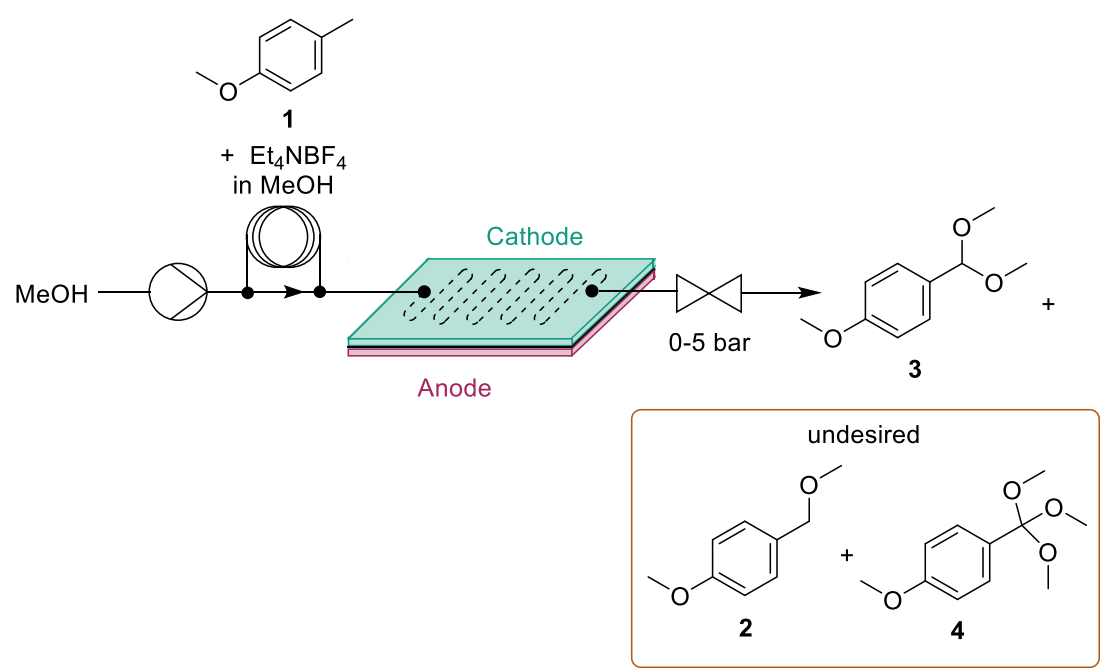




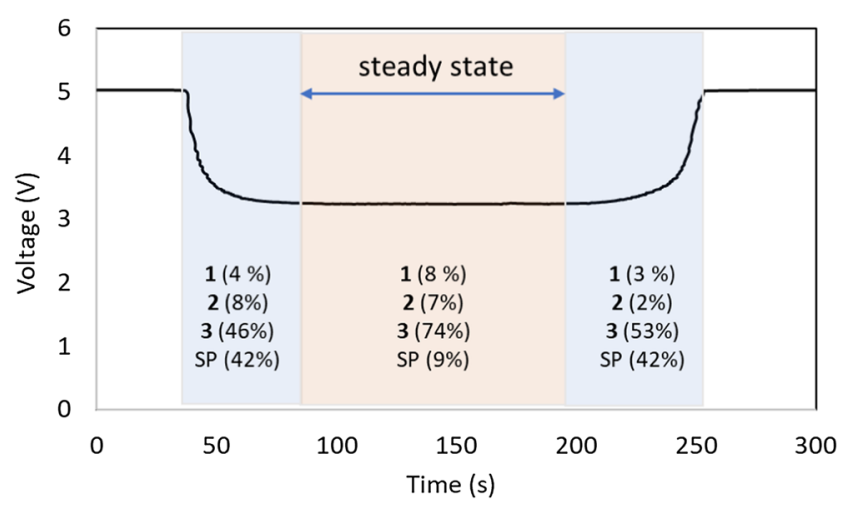

Fig. 3 Monitoring of the cell voltage during a constant current experiment and composition of the reaction solution outside of the steady-state fraction. SP, side-products

even electrode damage) a maximum voltage of $5 \mathrm{~V}$ was set in the power supply. Figure 3 shows the voltage profile recorded during the process. As the reaction mixture entered the flow cell, the voltage dropped to a value of $3.2 \mathrm{~V}$. When no electrolyte was present in the cell, the power supply reached the maximum of $5 \mathrm{~V}$ and switched to constant voltage. During the transient period until steady state is reached, all the current is applied to a small fraction of reaction mixture, leading to overoxidation. This was demonstrated by GC monitoring of the output stream before and after steady state. Notably, high amounts of side-products $(42 \%)$ were observed.

Under potentiostatic operation, the reaction selectivity is not affected by the reactant concentration. Thus, steady-state conditions are not required to apply electricity to the cell, which may be advantageous when only small amounts of starting material are available. When the reaction mixture enters the flow cell, the current will increase with the amount of electrolyte existing in the cell. Potentiostatic operations can lead to improved selectivities in some instances [36], as the potential can be tuned below the redox potential of sensitive functionalities. However, to achieve robust and reproducible results under potentiostatic conditions, a three-electrode configuration is typically required. As mentioned above, the cell voltage in a two-electrode arrangement can be affected by external factors such as temperature or small amounts of impurities on the electrode surface. Moreover, small changes in the cell voltage can lead to significant alterations in the cell current (Fig. 4a). This effect, less relevant in flow experiments with recirculation of the solution, is very important for singlepass continuous flow experiments in which a particular amount of charge to be applied to the reaction mixture is targeted.

To exemplify these potential issues under potentiostatic operation using a two-electrode configuration setup, the model reaction was carried out under constant voltage. A potential of $3.2 \mathrm{~V}$ was initially selected, which corresponded to the potential observed in a previous experiment under constant current (cf. Fig. 3). The same reaction conditions were utilized
(0.1 $\mathrm{M} 1$ and $0.1 \mathrm{M} \mathrm{Et}_{4} \mathrm{NBF}_{4}$ in $\mathrm{MeOH}$ ). Notably, the observed current (Fig. 4b) was significantly lower than expected. A value of 130-140 mA under steady-state conditions was recorded. In this case, as the current is not constant, the amount of charge transferred to the reaction mixture can be calculated by integrating the current value over the time period (see Eq. 2 in Fig. 4b). This can be easily done by numerical integration using any spreadsheet software (e.g., MS Excel) with the current vs time data. The amount of charge, in this case, $2.07 \mathrm{~F} / \mathrm{mol}$ was insufficient. Increasing the cell potential by 0.5 to $3.7 \mathrm{~V}$ essentially doubled the observed cell current and consequently the amount of charge (Fig. 4b). In this case, a small excess of current over the theoretical amount required $(4.04 \mathrm{~F} / \mathrm{mol})$ was applied.

\section{Importance of the interelectrode distance and current density}

The interelectrode gap has a significant influence on the performance of a flow cell. In general terms, it can be stated that narrower gaps lead to lower cell resistance, typically resulting

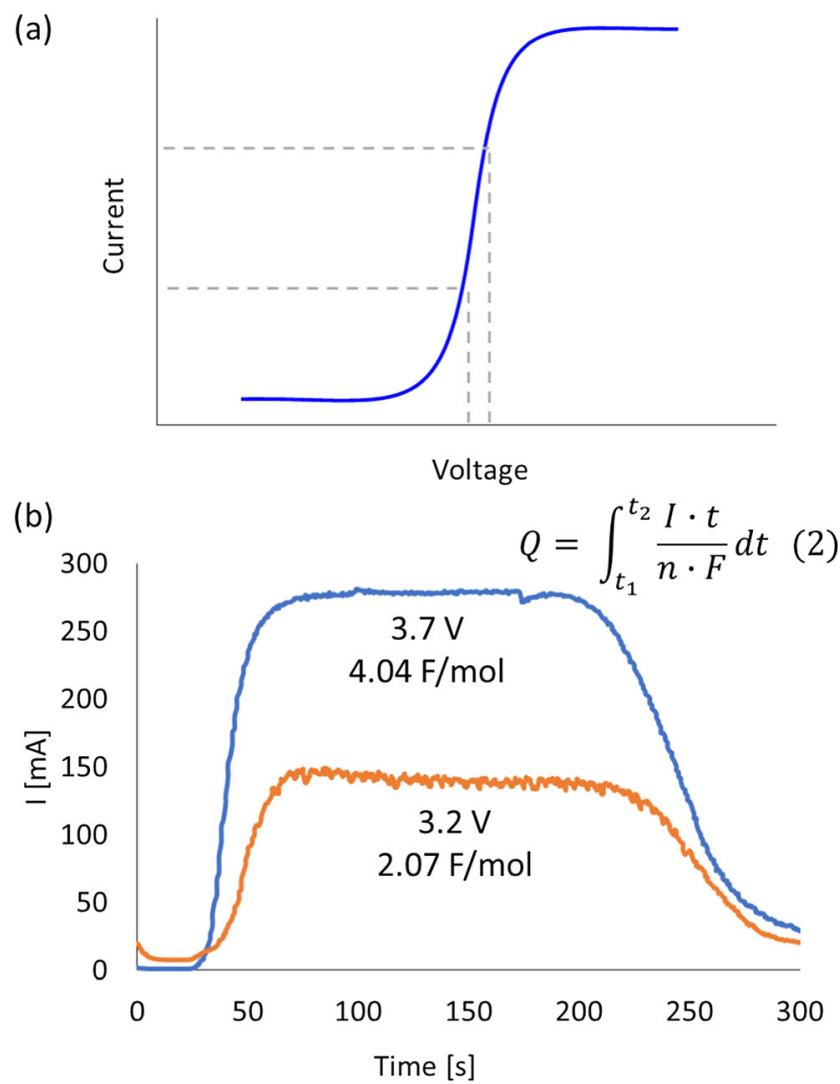

Fig. 4 a Typical current vs potential curve of an electrochemical cell. Small variations in the cell voltage can result in very large drifts in the cell current. b Monitoring of the current for the continuous methoxylation of 1 under constant voltage $(3.2 \mathrm{~V}$ and $3.7 \mathrm{~V})$ and equation for the calculation of the total amount of charge $Q(n=$ amount of substrate in mmol) 
in smaller amounts of supporting electrolyte being required to run the electrochemical reaction $[9,27]$. In addition, narrower gap cells exhibit larger electrode area to cell volume ratios. This ratio has a direct effect on the rate with which the electrolysis can be carried out [9].

Current and current density (current relative to the electrode area) are the parameters that define the cell productivity and one of the most important factors that characterize an electrochemical reaction, both in batch and flow mode. Electrochemical reactions typically perform better in terms of current efficiency and selectivity at low current densities. The development of flow cells and other scale-up strategies should therefore focus on the maximization of the current density that is possible to be applied to the reaction, in addition to the utilization of large electrode surface areas. Importantly, the interelectrode gap influences the current density values that can be applied to the cell: narrow gaps enable higher current densities (vide infra). This effect results in higher productivities for lower volume cells for a given electrode surface area (a narrower interelectrode distance provides a lower cell volume), which may sound counter-intuitive to the synthetic organic chemist.

We carried out the model flow electrochemical methoxylation of $\mathbf{1}$ using variable concentrations of supporting electrolyte and interelectrode spacers of different thickness (Fig. 5). As expected, the cell voltage was lower for the narrower interelectrode gaps even with a $0.1 \mathrm{M}$ concentration of $\mathrm{Et}_{4} \mathrm{NBF}_{4}$. As the concentration of supporting electrolyte was decreased, the cell voltage significantly incremented in the batch reactor ( $5 \mathrm{~mm}$ gap). The increase was less pronounced in the flow reactor with a $0.5-\mathrm{mm}$ interelectrode spacer. Notably, with a $0.1-\mathrm{mm}$ gap the supporting electrolyte concentration could be decreased down to $0.02 \mathrm{M}$ without any detectable increase in the cell voltage (Fig. 5). A 5 -fold decrease in the amount of a relatively costly substance could be achieved by transferring the electrochemical reaction to flow and reducing the interelectrode distance.

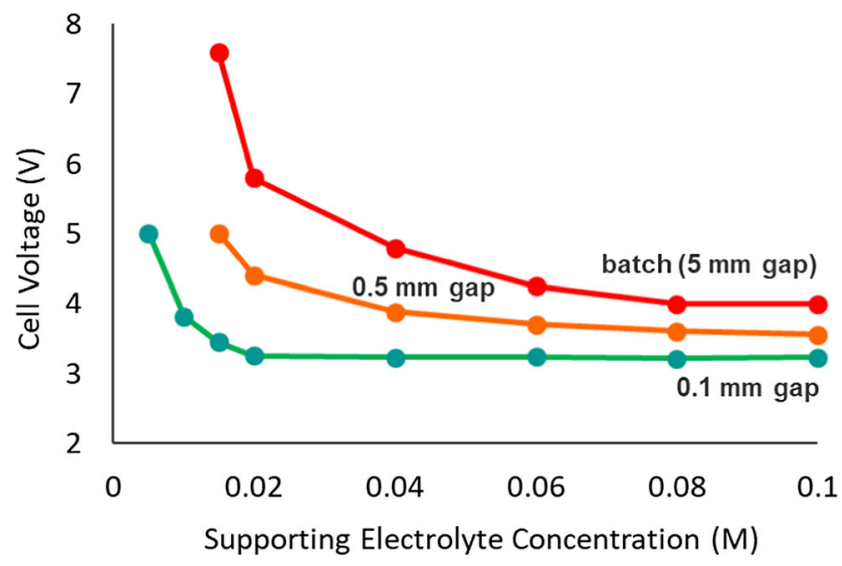

Fig. 5 Effect of the concentration of supporting electrolyte $\left(\mathrm{Et}_{4} \mathrm{NBF}_{4}\right)$ on the cell voltage during the methoxylation of $1(0.1 \mathrm{M}$ in $\mathrm{MeOH})$
We next turned our attention to the effect of both the interelectrode distance and the current density on the reaction conversion and selectivity. Four different interelectrode distances and flow rates were evaluated (Table 2). The cell current was set according to the flow rates to keep the amount of charge constant at $4 \mathrm{~F} / \mathrm{mol}$. As expected, the conversion and yield decreased with increasing current densities for all interelectrode spacers. With the thinnest spacer $(0.1 \mathrm{~mm})$, a decrease in the conversion from 96 to $88 \%$ and in the GC yield of $\mathbf{3}$ from 87 to $64 \%$ was observed when the current density was gradually increased from 11 to $43 \mathrm{~mA} / \mathrm{cm}^{2}$. The drop in the reaction performance was more pronounced with wider interelectrode gaps. Thus, with a 1-mm gap, the conversion decreased from 89 to $44 \%$, and the amount of $\mathbf{3}$ from 65 to $29 \%$ (Table 2).

The results collected in Table 2 also illustrate the effect of the interelectrode distance on the current density that could be applied to a flow cell. For example, analogous conversion and selectivity was achieved with a current density of $11 \mathrm{~mA} / \mathrm{cm}^{2}$ when the 1-mm gap was used (entry 1) and with $43 \mathrm{~mA} / \mathrm{cm}^{2}$ when the 0.1-mm spacer was utilized instead (entry 4) (ca. $89 \%$ conversion and $65 \%$ yield). The current increase enabled by the narrower interelectrode gap permitted to increment the flow rate and therefore the cell productivity from 200 to 800 $\mu \mathrm{L} / \mathrm{min}$. Thus, as mentioned above, flow cells display larger productivities for smaller reactor volumes on equal electrode surface area, due to the higher performance of cells with narrower interelectrode gaps.

\section{Flow reactor back-pressure in reactions with gaseous byproducts}

Most anodic oxidations utilize a proton source (e.g., water or an alcohol) as a convenient electron acceptor for the concurrent cathodic reduction. This generates stoichiometric amounts (1 equiv for a 2-electron process) of $\mathrm{H}_{2}$ gas as byproduct. While in batch the gas simply moves to the headspace, in continuous flow reactors, with no head space available, the generated $\mathrm{H}_{2}$ affects the cell performance. The behavior of the gas phase and its effect on the flow electrolysis has been studied in detail [37-39]. Gas generation typically results in gas/liquid segments in a flow reactor. As they do not conduct electricity, the presence of gas segments increases local current densities in the liquid phase, which has a negative effect on the cell performance. On the other hand, gas segments moving through the reactor channel influence the mass transfer. Depending on the flow regime, this might have a positive effect by promoting turbulence. Increasing the operating pressure of the flow cell has been suggested as a possible solution to minimize the issues associated with the generation of gas by reducing the size of the segments [37-39]. High pressure could also have a negative effect on the current 
Table 2 Effect of the interelectrode gap distance and the current density on the conversion and selectivity for the continuous electrochemical methoxylation of $\mathbf{1}^{\mathrm{a}}$

\begin{tabular}{|c|c|c|c|c|c|c|c|c|}
\hline \multirow[t]{3}{*}{ Entry } & \multirow[t]{3}{*}{ Flow rate $(\mu \mathrm{L} / \mathrm{min})$} & \multirow[t]{3}{*}{$I(\mathrm{~mA})$} & \multirow[t]{3}{*}{$j\left(\mathrm{~mA} / \mathrm{cm}^{2}\right)$} & \multirow[t]{3}{*}{$Q(\mathrm{~F} / \mathrm{mol})$} & \multicolumn{4}{|c|}{ Conv $1 /$ yield $3(\%)^{\mathrm{b}}$} \\
\hline & & & & & \multicolumn{4}{|c|}{ Interelectrode gap } \\
\hline & & & & & $0.1 \mathrm{~mm}$ & $0.25 \mathrm{~mm}$ & $0.5 \mathrm{~mm}$ & $1 \mathrm{~mm}$ \\
\hline 1 & 200 & 129 & 11 & 4 & $96 / 87$ & $89 / 71$ & $84 / 71$ & $89 / 65$ \\
\hline 2 & 400 & 257 & 21 & 4 & $92 / 74$ & $74 / 52$ & $67 / 49$ & $66 / 47$ \\
\hline 3 & 600 & 386 & 32 & 4 & $90 / 72$ & $72 / 48$ & $67 / 48$ & $59 / 39$ \\
\hline 4 & 800 & 515 & 43 & 4 & $88 / 64$ & $68 / 43$ & $47 / 28$ & $44 / 29$ \\
\hline
\end{tabular}

${ }^{a}$ Reaction conditions: $0.1 \mathrm{M}$ 4-methylanisole and $0.1 \mathrm{M} \mathrm{Et}_{4} \mathrm{NBF}_{4}$ in methanol. Flow setup depicted in Fig. 2 was utilized under constant current

${ }^{\mathrm{b}}$ Determined by GC-FID peak area percentage

${ }^{\mathrm{c}} C E$ current efficiency, calculated as the proportion of charge effectively utilized for methoxylation, including compounds $\mathbf{2 , 3}$, and $\mathbf{4}$

efficiency by incrementing the amount of $\mathrm{H}_{2}$ dissolved in the liquid phase, aiding its oxidation on the anode [40].

The electrochemical methoxylation of 1, a 4-electron process, generates two equivalents of $\mathrm{H}_{2}$ gas. For our model reaction conditions ( $0.1 \mathrm{M}$ concentration of $\mathbf{1}$ in $\mathrm{MeOH})$, approximately $2.2 \mathrm{~mL}$ of gas are generated per milliliter of reaction mixture. Using an adjustable BPR, the continuous flow reaction was evaluated under back-pressures ranging from 0 to 5 bar. A $0.5-\mathrm{mm}$ interelectrode gap distance was utilized in this case. As expected, the average cell potential decreased at higher pressure due to the smaller size of the gas segments that provoke increased cell resistance (Table 3). Interestingly, the reaction conversion, yield of $\mathbf{3}$, and the current efficiency gradually decreased with increasing pressures. This effect could be ascribed to large amount of $\mathrm{H}_{2}$ dissolved in the liquid phase, resulting in undesired oxidation of the gas to protons. This pressure effect has been described by Attour et al. [40], although in their study higher pressure had to be applied in order to observe this decrease in cell efficiency. Another interesting effect was observed in the cell voltage when back-pressure was applied (Fig. 6). Gas and liquid slugs typically produce different resistance for passing through a BPR. Gas segments can pass more easily than liquid segments, which provokes pressure oscillations in the system. These oscillations translate to the cell potential, likely due to expansioncompression of the gas segments and detachment of small gas bubbles from the electrode surface.

\section{Batch vs flow cell efficiency}

Even though the study described herein is not representative of large-scale operation (only $0.3-\mathrm{mmol}$ scale reactions were carried out in batch), important differences between the reaction performance in batch and flow mode could be observed.

The batch reactions were carried out using a current density of $13 \mathrm{~mA} / \mathrm{cm}^{2}$ and a $5-\mathrm{mm}$ interelectrode distance. The relatively small amount of reaction mixture processed $(3 \mathrm{~mL}, 0.3$ mmol) required 96 min of electrolysis time for an amount of charge of $4 \mathrm{~F} / \mathrm{mol}$. Yet, only moderate conversions were achieved with the theoretical amount, and a 50\% excess (6 $\mathrm{F} / \mathrm{mol}$ ) was required to obtain good conversions over a 144min time period (Table 1). The current efficiency for the batch reaction was ca. 60\%. Using a similar current density (Table 2, entry 1) in continuous flow with a $0.1-\mathrm{mm}$ interelectrode gap distance resulted in excellent conversion and yield using a
Table 3 Effect of the flow cell back-pressure on the conversion, selectivity, and current efficiency for the continuous electrochemical methoxylation of $1^{\mathrm{a}}$

\begin{tabular}{lllll}
\hline Entry & Back-pressure (bar) & Average voltage (V) & Conv/yield 3 (\%) & CE (\%) $)^{\mathrm{c}}$ \\
\hline 1 & 0 & 3.54 & $76 / 60$ & 81 \\
2 & 1 & 3.49 & $75 / 61$ & 77 \\
3 & 2 & 3.48 & $74 / 60$ & 75 \\
4 & 3 & 3.43 & $74 / 57$ & 74 \\
5 & 4 & 3.42 & $70 / 54$ & 70 \\
6 & 5 & 3.30 & $71 / 55$ & 71 \\
\hline
\end{tabular}

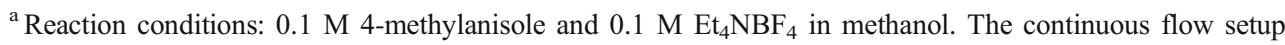
depicted in Fig. 2 was utilized with $400 \mu \mathrm{L} / \mathrm{min}$ and $257 \mathrm{~mA}$ (4 F/mol) constant current

${ }^{\mathrm{b}}$ Determined by GC-FID peak area percentage

${ }^{\mathrm{c}} C E$ current efficiency, calculated as the proportion of charge effectively utilized for methoxylation, including compounds 2,3 , and 4 
charge of $4 \mathrm{~F} / \mathrm{mol}$. In this case, the current efficiency was nearly quantitative. The time required to process the same amount of reaction mixture $(3 \mathrm{~mL})$ in flow under these conditions was $15 \mathrm{~min}$. Importantly, the narrow interelectrode gap enabled higher current densities in the flow cell. A 4-fold increase of current density resulted in very good conversion also using $4 \mathrm{~F} / \mathrm{mol}$. In this case, $3 \mathrm{~mL}$ of reaction mixture could be processed in $3.75 \mathrm{~min}$, with a productivity ca. 40 times compared with the batch reactor. The comparison between the efficiency of the batch and flow processes is summarized in Table 4.

\section{Conclusions}

In summary, the electrochemical methoxylation of 4methylanisole has been performed in batch and continuous flow mode. They key parameters that need to be considered for the translation of the batch procedure to a single-pass flow protocol have been described in detail. Galvanostatic or potentiostatic operation can both be applied, although galvanostatic operation provides more robust results. Under galvanostatic mode, it is important to apply current only when steady-state conditions are reached to avoid high amounts of overoxidation products, including that of the solvent, and possible damage to the electrodes. The most important parameters defining the efficiency of the flow cell are the interelectrode distance and the current density. Lower current densities lead to higher reaction performance. The interelectrode gap should

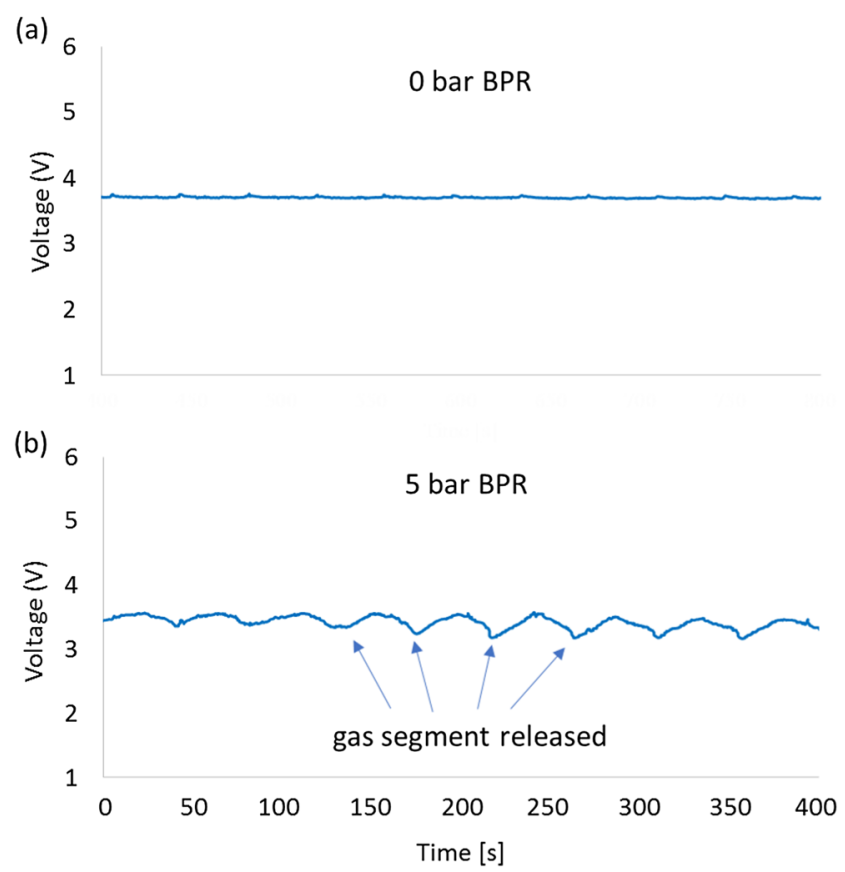

Fig. 6 Behavior of the cell potential during electrolysis with no backpressure (a) and with a back-pressure of 5 bar (b)
Table 4 Comparison of the current efficiency and cell productivity obtained for the batch and flow electrochemical methoxylation of 1

\begin{tabular}{lll}
\hline & Batch & Flow \\
\hline Interelectrode distance (mm) & 5 & 0.1 \\
Current (mA) & 20 & 515 \\
Current efficiency (\%) & 60 & 99 \\
Cell productivity (mmol/h) & 0.12 & 4.8 \\
\hline
\end{tabular}

be as narrow as possible. Narrow gaps enable increased current efficiency and maximize the cell productivity even though the cell volume is lower. Moreover, narrower gaps permit the utilization of very low amounts of supporting electrolyte. Application of back-pressure reduces the cell resistance and therefore its voltage. However, in this example, application of pressure has shown to be counterproductive, probably due to the increment of $\mathrm{H}_{2}$ gas dissolved in the liquid phase causing a loss of current efficiency due to its oxidation. Even for a very small scale reaction $(3 \mathrm{~mL})$, the productivity and current efficiency are significantly higher for the flow cell as compared with the batch equipment.

We hope this guide will be useful for synthetic organic chemists that want to enter the field of continuous flow electroorganic synthesis.

\section{Experimental section}

General remarks GC-FID analysis was performed on a ThermoFisher Focus GC with a flame ionization detector, using a TR-5MS column $(30 \mathrm{~m} \times 0.25 \mathrm{~mm}$ ID $\times 0.25 \mu \mathrm{m})$ and helium as carrier gas $\left(1 \mathrm{~mL} \min ^{-1}\right.$ constant flow). The injector temperature was set to $280^{\circ} \mathrm{C}$. After $1 \mathrm{~min}$ at $50^{\circ} \mathrm{C}$, the temperature was increased by $25^{\circ} \mathrm{C} \mathrm{min}^{-1}$ to $300^{\circ} \mathrm{C}$ and kept constant at $300{ }^{\circ} \mathrm{C}$ for $4 \mathrm{~min}$. The detector gases for flame ionization were hydrogen and synthetic air (5.0 quality). GCMS spectra were recorded using a ThermoFisher Focus GC coupled with a DSQ II (EI, $70 \mathrm{eV}$ ). A TR-5MS column (30 m $\times 0.25 \mathrm{~mm} \times 0.25 \mu \mathrm{m})$ was used, with helium as carrier gas $(1$ $\mathrm{mL} \min ^{-1}$ constant flow). The injector temperature was set to $280{ }^{\circ} \mathrm{C}$. After $1 \mathrm{~min}$ at $50{ }^{\circ} \mathrm{C}$, the temperature was increased by $25^{\circ} \mathrm{C} \mathrm{min}{ }^{-1}$ to $300{ }^{\circ} \mathrm{C}$ and kept at $300{ }^{\circ} \mathrm{C}$ for $3 \mathrm{~min}$. All chemicals were purchased from standard commercial vendors and utilized without further purification. Batch electrolysis experiments were carried out in an IKA ElectraSyn 2.0 instrument. Continuous flow experiments were carried out in an Ion reactor (Vapourtec Ltd). A programmable power supply (PeakTech 6070) was utilized to provide electricity to the flow setup.

Batch methoxylation of 4-methylanisole In a 5-mL vial 4methylanisole $(0.3 \mathrm{mmol})$, tetraethylammonium tetrafluoroborate $(0.3 \mathrm{mmol})$ and methanol $(3 \mathrm{~mL})$ were added. The 
mixture was stirred until the solid was completely dissolved and then was electrolyzed using an IKA ElectraSyn 2.0 electrochemical reactor. After the desired amount of charge had been passed, an aliquot of the crude reaction mixture was analyzed by GC-FID.

\section{Continuous flow methoxylation of 4-methylanisole} Continuous flow experiments were carried out using the setup depicted in Fig. 2. Reactants solutions were prepared by dissolving 4-methylanisole $(0.1 \mathrm{M})$ and the corresponding amount of tetraethylammonium tetrafluoroborate in methanol. Samples were introduced in the flow electrochemical cell (Vapourtec Ion reactor) using a sample loop injector $(V=1.5$ $\mathrm{mL}$ ). The flow cell consisted of two $5 \times 5 \mathrm{~cm}$ parallel electrodes separated by a PTFE or FEP spacer featuring a reactor channel [35]. The crude reaction mixture collected from the reactor output was analyzed by GC-FID.

Acknowledgments The authors thank Vapourtec Ltd. for the provision of an Ion electrochemical reactor.

Funding information Open access funding provided by University of Graz. The CC FLOW project (Austrian Research Promotion Agency FFG No. 862766) is funded through the Austrian COMET Program by the Austrian Federal Ministry of Transport, Innovation, and Technology (BMVIT), the Austrian Federal Ministry of Science, Research and Economy (BMWFW), and by the State of Styria (Styrian Funding Agency SFG).

\section{Compliance with ethical standards}

Conflict of interest The authors declare that they have no conflict of interest.

Open Access This article is licensed under a Creative Commons Attribution 4.0 International License, which permits use, sharing, adaptation, distribution and reproduction in any medium or format, as long as you give appropriate credit to the original author(s) and the source, provide a link to the Creative Commons licence, and indicate if changes were made. The images or other third party material in this article are included in the article's Creative Commons licence, unless indicated otherwise in a credit line to the material. If material is not included in the article's Creative Commons licence and your intended use is not permitted by statutory regulation or exceeds the permitted use, you will need to obtain permission directly from the copyright holder. To view a copy of this licence, visit http://creativecommons.org/licenses/by/4.0/.

\section{References}

1. Yan M, Kawamata Y, Baran PS (2017) Synthetic organic electrochemical methods since 2000: on the verge of a renaissance. Chem. Rev. 117:13230-13319

2. Echeverria PG, Delbrayelle D, Letort A, Nomertin F, Perez M, Petit L (2018) The spectacular resurgence of electrochemical redox reactions in organic synthesis. Aldrichimica Acta. 51:3-19
3. Wiebe A, Gieshoff T, Möhle S, Rodrigo E, Zirbes M, Waldvogel SR (2018) Electrifying organic synthesis. Angew. Chem. Int. Ed. 57: 5594-5619

4. Schäfer HJ (2011) Contributions of organic electrosynthesis to green chemistry. C. R. Chimie. 14:745-765

5. Horn EJ, Rosen BR, Baran PS (2016) Synthetic organic electrochemistry: an enabling and innately sustainable method ACS Cent. Sci. 25:302-308

6. Yoshida J, Nagaki A (2013) Electrochemical reactions in microreactors, in microreactors in preparative chemistry (Eds.: Reschetilowski W). Wiley-VCH, Weinheim

7. Watts K, Baker A, Wirth T (2014) Electrochemical synthesis in microreactors. J. Flow Chem. 4:2-11

8. Atobe M, Tateno H, Matsumura Y (2018) Applications of flow microreactors in electrosynthetic processes. Chem. Rev. 118: $4541-4572$

9. Pletcher D, Green RA, Brown RCD (2018) Flow electrolysis cells for the synthetic organic chemistry laboratory. Chem. Rev. 118: 4573-4591

10. Noël T, Cao Y Laudadio, G. The fundamentals behind the use of flow reactors in electrochemistry. Acc. Chem. Res. https://doi.org/ 10.1021/acs.accounts.9b00412

11. Wendt H, Kreysa G (1999) Electrochemical engineering. Science and Technology in Chemical and other Industries. Springer-Verlag, Berlin, Heidelerg

12. Ralph TR, Hitchman ML, Millington JP, Walsh FC (1996) Mass transport in an electrochemical laboratory filterpress reactor and its enhancement by turbulence promoters. Electrochim. Acta 41:591603

13. Pletcher D, Walsh FC (1993) Industrial ElectrochemistrySecond edn. Springer, Dordrecht

14. Baxendale IR (2013) The integration of flow reactors into synthetic organic chemistry. J. Chem. Technol. Biotechnol. 88:519-552

15. Britton J, Raston CL (2017) Multi-step continuous-flow synthesis. Chem. Soc. Rev. 46:1250-1271

16. Suga S, Okajima M, Fujiwara K, Yoshida J (2005) Electrochemical combinatorial organic syntheses using microflow systems. QSAR Comb. Sci. 24:728-741

17. Horcajada R, Okajima M, Suga S, Yoshida J (2005) Microflow electroorganic synthesis without supporting electrolyte. Chem. Commun. 1303-1305

18. Green R, Brown R, Pletcher D, Harji B (2016) An extended channel length microflow electrolysis cell for convenient laboratory synthesis. Electrochem. Commun. 73:63-66

19. Green R, Brown R, Pletcher D (2016) Electrosynthesis in extended channel length microfluidic cells. J. Flow Chem. 6:191-197

20. Attour A, Rode S, Ziogas A, Matlosz M, Lapicque F (2008) Thingap cell for selective oxidation of 4-methylanisole to 4-methoxybenzaldehyde-dimethylacetal. J. Appl. Electrochem. 38:339-347

21. Küpper M, Hessel V, Löwe H, Stark W, Kinkel J, Michel M, Schmidt-Traub H (2003) Micro reactor for electroorganic synthesis in the simulated moving bed-reaction and separation environment. Electrochim. Acta 48:2889-2896

22. Islam M, Kariuki BM, Shafiq Z, Wirth T, Ahmed N (2019) Efficient electrosynthesis of thiazolidin-2-imines via oxysulfurization of thiourea-tethered terminal alkenes using the flow microreactor. Eur. J. Org. Chem.:1371-1376

23. Folgueiras-Amador AA, Philipps K, Guilbaud S, Poelakker J, Wirth T (2017) An easy-to-machine electrochemical flow microreactor: efficient isoindolinone synthesis and flow functionalization. Angew. Chem. Int. Ed. 56:15446-15450

24. Laudadio G, de Smet W, Struik L, Cao Y, Noël T (2018) Design and application of a modular and scalable electrochemical flow microreactor. J. Flow. Chem. 8:157-165 
25. Gütz C, Stenglein A, Waldvogel SR (2017) Highly modular flow cell for electroorganic synthesis. Org. Process. Res. Dev. 21:771778

26. Fuller TF, Harb JN (2018) Electrochemical engineering. John Wiley and Sons, Inc., Hoboken

27. Green RA, Brown RCD, Pletcher D (2015) Understanding the performance of a microfluidic electrolysis cell for routine organic electrosynthesis. J. Flow. Chem. 5:31-36

28. Walsh FC, Pletcher D (2014) Electrochemical engineering and cell design, in Developments in electrochemistry: science inspired by Martin Fleischmann (Eds.: Pletcher D, Tian ZQ, Williams DE). John Wiley \& Sons Ltd, Chichester

29. Yan M, Kawamata Y, Baran PS (2018) Synthetic organic electrochemistry: calling all engineers. Angew. Chem. Int. Ed. 57:4149-4155

30. Pletcher D (2018) Organic electrosynthesis - a road to greater application. A mini review. Electrochem. Commun. 88:1-4

31. Attour A, Rode S, Lapicque F, Ziogas A, Matlosz M (2008) Thingap single-pass high-conversion reactor for organic electrosynthesis. J. Electrochem. Soc. 155:E201-E206

32. Ziogas A, Kolb G, O'Connell M, Attour A, Lapicque F, Matlosz M, Rode S (2009) Electrochemical microstructured reactors: design and application in organic synthesis. J. Appl. Electrochem. 39:2297-2313

33. Kuleshova J, Hill-Cousins JT, Birkin PR, Brown RCD, Pletcher D, Underwood TJ (2011) A simple and inexpensive microfluidic electrolysis cell. Electrochim. Acta 56:4322-4326

34. Roth GP, Stalder R, Long TR, Sauer DR, Djuric SW (2013) Continuous-flow microfluidic electrochemical synthesis: investigating a new tool for oxidative chemistry. J. Flow Chem. 3:34-40

35. Amri N, Skilton RA, Guthrie D, Wirth T (2019) Efficient flow electrochemical alkoxylation of pyrrolidine-1-carbaldehyde. Synlett. 30:1183-1186

36. Laudadio G, NJW S, Lanting MD, Knoops B, Hessel V, Noël T (2017) An environmentally benign and selective electrochemical oxidation of sulfides and thiols in a continuous-flow microreactor. Green Chem. 19:4061-4066

37. Taqieddin A, Nazari R, Rajic L, Alshawabkeh A (2017) Reviewphysicochemical hydrodynamics of gas bubbles in two phase electrochemical systems. J. Electrochem. Soc. 164:448-459

38. Sequeira CAC, Santos DFM, Šljukić B, Amaral L (2013) Physics of electrolytic gas evolution. Braz. J. Phys. 43:199-208

39. Křištál J, Kodým R, Bouzek K, Jiřičný V (2008) Electrochemical microreactor and gas-evolving reactions. Electrochem. Commun. 10:204-207

40. Attour A, Dirrenberger P, Rode S, Ziogas A, Matlosz M, Lapicque F (2011) A high pressure single-pass high-conversion electrochemical cell for Intensification of organic electrosynthesis processes.

Chem. Eng. Sci. 66:480-489Publisher's note Springer Nature remains neutral with regard to jurisdictional claims in published maps and institutional affiliations.

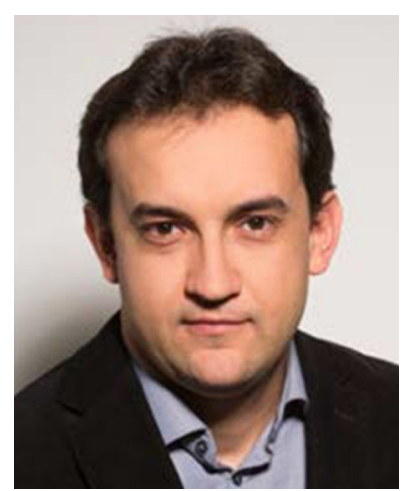

David Cantillo obtained his $\mathrm{PhD}$ from the University of Extremadura, Spain in 2011. His $\mathrm{PhD}$ focused on the experimental and theoretical study of 1,3-dipolar cycloadditions of mesoionic compounds. In 2011 he joined the Kappe Group at the University of Graz as a postdoctoral associate. Since this time his research interests and experience involve computational chemistry, photoredox catalysis and multistep API synthesis. David Cantillo is an Area Leader at the Research Center Pharmaceutical Engineering Gmbh (RCPE) and in 2018 joined the faculty of University of Graz as Assistant Professor. His current research focuses on flow electrochemistry. 